\title{
Endovascular treatment of infrapopliteal arteries: angioplasty vs stent in the drug-eluting era
}

\author{
Fabrizio Fanelli • Alessandro Cannavale
}

Received: 22 August 2013 /Revised: 16 December 2013 / Accepted: 19 December 2013 / Published online: 30 January 2014

(C) European Society of Radiology 2014

\begin{abstract}
To analyse data comparing drug-eluting devices versus non-coated devices in the treatment of vascular disease in the infrapopliteal region. All data available in the literature (16 studies were included) comparing drug-eluting stents (DESs) and drug-eluting balloons (DEBs) versus bare-metal stents (BMSs) and conventional balloons were analysed. For each single study, primary and secondary endpoints were reported. As comparative studies between DEBs and DESs were not available, a technical evaluation of the advantages and disadvantages of both were also included. Besides the limitations of the published studies, all of them were reporting interesting results for the new generation devices (DEB and DES). DES: primary patency at 1 year comprised between $75.0 \%$ and $86 \%$; target lesion revascularisation between $8.7 \%$ and $13.8 \%$. DEB: primary patency comprised between $71 \%$ and $84.6 \%$ at 12 months; target lesion revascularisation between $15.3 \%$ and $17.6 \%$. However, limb salvage rates were not always higher using a DEB rather than a standard percutaneous transluminal angioplasty (PTA); a clinical improvement for patients treated with DEB was demonstrated only in the Leipzig registry. On the basis of the results available, the drug-eluting devices produced better results. DEB can be considered the leading approach in below-the-knee disease. A comparative evaluation with DES is mandatory in the future.

Key Points

- We present data about advanced endovascular treatment of peripheral artery disease.

- This provides an update on drug-eluting devices in infrapopliteal vascular disease.
\end{abstract}

F. Fanelli $(\square) \cdot$ A. Cannavale

Vascular and Interventional Radiology Unit, Department of

Radiological Sciences, "Sapienza" - University of Rome, 324 Viale

Regina Elena, 00161 Rome, Italy

e-mail: fabrizio.fanelli@uniroma1.it

A. Cannavale

e-mail: alessandro.cannavale@hotmail.com
- Drug-eluting devices (DEB/DES) show promising results compared with traditional ones.

\begin{tabular}{|c|c|}
\hline Abbr & iations \\
\hline BMS & bare-metal stent \\
\hline DEB & drug-eluting balloon \\
\hline DES & drug-eluting stent \\
\hline PTA & percutaneous transluminal angioplasty \\
\hline SFA & superficial femoral artery \\
\hline
\end{tabular}

\section{Introduction}

Endovascular therapy with drug-eluting devices has recently been gaining more and more success in different vascular districts as well as in the below-the-knee region [1-5].

Patients with infrapopliteal arterial disease are generally considered difficult to several revascularisation techniques because of the common presence of multi-vessel atherosclerotic disease, long lesions, small calibre and highly calcified arteries, higher incidence of occlusions versus stenoses, diabetes and high Rutherford category. Moreover, the below-theknee area is subject to a higher risk of restenosis, thrombosis and amputation than the other vascular districts [6].

In such patients the main goals of the endovascular technique are not only to improve the patency rate (defined as freedom from restenosis $>50 \%$ ) but also the clinical outcome. As a consequence, drug-eluting devices can play a primary role in reducing target lesion revascularisation, improving the limb salvage rate and ulcer healing.

The correlation between vessel patency and limb salvage/ ulcer healing is well known; an improved distal flow can noticeably improve the clinical outcome. And if ulcer healing is achieved, restenosis may not produce further critical limb 
ischaemia. However, some doubts are still present regarding time to healing [7].

As reported by some authors, a higher number of patent vessels increases the blood flow with greater possibility of the ulcer healing. They introduced a simple concept: one patent vessel could be enough, but two patent vessels are better than one and three patent vessels are better than two. Moreover, the patency of the tibial vessels seems to be more important than that of the peroneal artery $[2,3]$.

We also have to keep in mind that inflow plays an important role, and in patients with critical limb ischaemia, a patent superficial femoral artery (SFA) is also mandatory.

Drug-eluting stents (DESs) and drug-eluting balloons (DEBs) represent "two sides of the same coin" for the ability to deliver anti-proliferative drugs locally. The main goal of the drug is to inhibit the neo-intimal reaction to the vessel wall trauma caused by either balloon dilation or stent deployment.

Recently, several clinical studies and randomised control trials have been performed to answer some challenging questions:

- Are drug-eluting devices more efficient than conventional ones in the treatment of below-the-knee vascular disease?

- Are they able to guarantee clinical improvement?

- Do they increase the long-term patency rates?

- Can they be considered safe, with a low rate of major adverse events?

Let us try to find an answer to those questions by looking at the most recent results reported in the literature regarding both DESs and DEBs (Table 1).

\section{Drug-eluting stent (DES)}

The DES can be considered the "father" of drug-eluting devices; its ability to deliver anti-proliferative drugs locally was initially reported in the cardiology field [8].

This is the reason why, up to the present day, more studies have been performed using DESs than DEBs in the below-theknee region.

The results in the cardiological field were very promising and stimulated the idea that these devices can also be applied in the peripheral vessels. Consequently initial studies in the below-the-knee region were carried out using coronary devices [8].

So far, standard angioplasty (PTA) and use of bare-metal stents (BMSs) have been considered the "standard treatment of care" for below-the-knee disease, but the results have not been so good [4].

To compare the efficacy of DES and BMS, four randomised controlled trials have been published: PaRADISE, DESTINY, YUKON-BTX and ACHILLES [5, 9-11].
The PaRADISE (Preventing Amputations Using DrugEluting Stents) [5] was the first non-randomised trial, in which a cohort of 106 patients treated with DES was prospectively studied and compared with historical data from the TASC II (Trans-Atlantic Inter-Society Consensus II) document and level-1 evidence from the BASIL (Bypass versus angioplasty in severe ischaemia of the leg) trial $[5,12,13]$. Primary endpoints were rates of limb salvage, amputation and major adverse events after 3 years of follow-up. An amputation rate of $6 \%$ at 3 years was reported in those patients treated with DES with symptoms resolved in $99 \%$ of non-amputated limbs. The 3-year limb salvage rate was $94 \%$, with wound healing and relief of resting pain in $93 \%$ of patients. Among patients alive at 3 years, major adverse events occurred in $4 \%$ of them and in $12 \%$ among those who died.

However, some study limitations should be considered, such as the non-randomisation of the procedures and nonstandardisation of the PTA protocols.

More recently another trial on critical limb ischaemia has been published: the DESTINY (Drug Eluting Stents in the Critically Ischemic Lower Leg) trial, which is a prospective, randomised, controlled, multicentre European trial; 74 patients were treated with an everolimus-eluting stent and 66 patients were treated with BMS [9].

The 1-year angiographic results showed a primary patency rate of $85.2 \%$ for DES versus $54 \%$ for BMS $(P<0.0001)$. Also, target lesion revascularisation was significantly lower for DES ( $8.7 \%$ DES vs $33.6 \%$ BMS; $P=0.01)$. Nevertheless, clinical follow-up did not show a significant difference between the two groups regarding improvement of Rutherford class and survival rates.

The YUKON-BTX (Drug-Eluting Stent Below the KneeRandomised Double-Blind Study) [10] analysed the following primary composite endpoints: event-free survival at 3 years of follow-up, defined as freedom from target limb amputation, target vessel revascularisation, myocardial infarction and death. Eighty-two patients were randomly assigned to receive the polymer-free sirolimus-eluting stent and 79 were assigned to receive the BMS.

The overall event-free survival rate was higher for sirolimus-eluting stents $(65.8 \%)$ than for BMS (44.6\%; $\log$-rank $P=0.02)$. Freedom from target limb amputation had significantly different results: $97.4 \%$ in the sirolimus-eluting stents group versus $87.8 \%$ in the BMS group $(P=0.03)$. Also, limb salvage (sirolimus-eluting stents $98.7 \%$ vs BMS 94.6\%) and clinically driven target vessel revascularisation (sirolimuseluting stents $9.2 \%$ vs BMS $20 \%$ ) showed clearly different results for the two groups in favour of sirolimus-eluting stents $(P>0.05)$. In this randomised controlled trial, both patients with critical limb ischaemia (46.6\%) and intermittent claudication (IC) were enrolled. However, in both groups there was no significant difference in event-free survival rates between sirolimus-eluting stents and BMSs (critical limb ischaemia: 
Table 1 At-a-glance results of the leading studies about endovascular treatment of below-the-knee artery disease

\begin{tabular}{|c|c|c|c|c|}
\hline & Drug-eluting balloon & Standard balloon & Drug-eluting stent & Bare-metal stent \\
\hline $\begin{array}{l}\text { Primary patency rate } \\
\quad(\%)\end{array}$ & $\begin{array}{l}\text { - Debellum: (12 mo): } 84.6 \\
\text { - Leipzig registry (3 mo): } \\
72.6 \\
\text { - DEBATE RCT (12 mo): } 73\end{array}$ & $\begin{array}{l}\text { Debellum }(12 \mathrm{mo}): 41.1 \\
\text { Leipzig registry }(3 \mathrm{mo}): 31.2 \\
\text { - DEBATE RCT }(12 \mathrm{mo}): 26 \\
\text { - ACHILLES (12 mo):57.1 }\end{array}$ & $\begin{array}{l}\text { - Karnabatidis (3 y): } 29.7 \\
\text { - YUKON (12 mo): } 80.6 \\
\text { - ACHILLES (12 mo): } 75.0 \\
\text { - DESTINY (12 mo): } 85.2\end{array}$ & $\begin{array}{l}\text { - Karnabatidis }(3 \text { y): } 20.6 \\
\text { - YUKON (12 mo): } 55.6 \\
\text { - BBTK study: } 6 \text { mo: } 79.8 \\
\text { 12 mo: } 72.4 \\
\text { - DESTINY (12 mo): } 54.3\end{array}$ \\
\hline TLR (\%) & $\begin{array}{l}\text { - Debellum (12 mo): } 15.3 \\
\text { - Leipzig registry (12 mo): } \\
\quad 17.3 \\
\text { - DEBATE RCT (12 mo): } \\
\quad 18.5\end{array}$ & $\begin{array}{l}\text { Debellum: }(12 \mathrm{mo}): 47.0 \\
\text { Leipzig registry }(3 \mathrm{mo}): 50 \\
\text { - DEBATE RCT }(12 \mathrm{mo}): \\
43.3 \\
\text { ACHILLES (12 mo): } 16.5\end{array}$ & $\begin{array}{l}\text { - Karnabatidis ( } 3 \mathrm{y}): 18.9 \\
\text { - YUKON (12 mo): } 13.8 \\
\text { - DESTINY (12 mo): } 8.7 \\
\text { - ACHILLES (12 mo): } 10\end{array}$ & $\begin{array}{l}\text { - Karnabatidis (3 y): } 32.5 \\
\text { - YUKON (12 mo): } 13 \\
\text { - BBTK study (12 mo): } 23 \\
\text { - DESTINY (12 mo): } 33.6\end{array}$ \\
\hline $\begin{array}{l}\text { Late lumen loss } \\
\quad(\mathrm{mm})\end{array}$ & $\begin{array}{l}\text { - Debellum: } 12 \text { mo: } 0.66 \pm 0.9 \\
\text { - Leipzig registry: n.a. } \\
\text { - DEBATE (12 mo): n.a. }\end{array}$ & $\begin{array}{l}\text { Debellum: } 12 \text { mo: } 1.69 \pm 1.5 \\
\text { Leipzig registry: n.a. } \\
\text { - DEBATE RCT (12 mo): n.a. } \\
\text { - ACHILLES (12 mo): } 0.4 \pm \\
\quad 1.0^{\text {a }}\end{array}$ & $\begin{array}{l}\text { - Karnabatidis et al.: n.a. } \\
\text { - YUKON (12 mo): n.a. } \\
\text { - ACHILLES (12 mo): } 0.5 \pm 1.1^{\text {a }} \\
\text { - DESTINY (12 mo): } 0.78 \pm \\
\quad 0.63^{\text {b }}\end{array}$ & $\begin{array}{l}\text { Karnabatidis et al.: n.a. } \\
\text { - YUKON (12 mo): n.a. } \\
\text { - DESTINY (12 mo): } 1.41 \pm \\
0.89^{\text {b }}\end{array}$ \\
\hline Re-occlusion & $\begin{array}{l}\text { - Debellum (12 mo): } 0 \\
\text { - DEBATE RCT (12 mo): } 17 \\
\text { - Leipzig reg (3 mo): } 8.3\end{array}$ & $\begin{array}{l}\text { Debellum (12 mo): } 9.1 \\
\text { - DEBATE RCT (12 mo): } \\
55 \\
\text { - Leipzig reg ( } 3 \text { mo): n.a. }\end{array}$ & $\begin{array}{l}\text { - Karnabatidis et al.: n.a. } \\
\text { - YUKON : n.a. } \\
\text { - DESTINY: n.a. } \\
\text { - ACHILLES: n.a. }\end{array}$ & $\begin{array}{l}\text { - Karnabatidis et al.: n.a. } \\
\text { - YUKON: n.a. } \\
\text { - DESTINY: n.a. } \\
\text { - ACHILLES: n.a. }\end{array}$ \\
\hline $\begin{array}{r}\text { Limb salvage, \% } \\
\text { (pts with CLI) }\end{array}$ & $\begin{array}{l}\text { - Debellum (12 mo): } 100 \\
\text { - Leipzig registry (12 mo): } \\
\text { 95.6 } \\
\text { - DEBATE RCT (12 mo): } 100\end{array}$ & $\begin{array}{l}\text { - Debellum (12 mo): } 96 \\
\text { - Leipzig registry }(12 \mathrm{mo}) \text { : } \\
100 \\
\text { - DEBATE RCT }(12 \mathrm{mo}): 98.5\end{array}$ & $\begin{array}{l}\text { - Karnabatidis ( } 3 \text { y): } 77.1 \\
\text { - YUKON (12 mo): } 98.7 \\
\text { - ACHILLES (12 mo): } 86.2 \\
\text { - DESTINY (12 mo): } 98.6\end{array}$ & $\begin{array}{l}\text { - Karnabatidis ( } 3 \text { y): } 86.9 \\
\text { - YUKON (12 mo): } 94.6 \\
\text { - ACHILLES (12 mo): } 80.0 \\
\text { - DESTINY (12 mo): } 97\end{array}$ \\
\hline
\end{tabular}

$T L R$ target lesion revascularisation, $R C T$ randomised controlled trial, $C L I$ critical limb ischaemia, late lumen loss the minimum lumen diameter (MLD) post-procedure minus MLD at follow-up, pts patients, mo months, $y$ years, $n$.a. not available

${ }^{a}$ The comparison between groups did not have a significantly different result $(P>0.05)$

${ }^{\mathrm{b}}$ The comparison between groups had a significantly different result $(P<0.05)$

$57.9 \%$ sirolimus-eluting stents vs $32.3 \% \mathrm{BMSs} ; P=0.07$ / IC: $71.1 \%$ sirolimus-eluting stents vs $50 \%$ BMSs; $P=0.07$ ). Amputation rate $(2.6 \%$ vs $12.2 \% ; P=0.03)$ and mean improvement in Rutherford class (two classes in the sirolimuseluting stent group and one class in the BMS group; $P=$ 0.0006) were better in those patients treated with sirolimuseluting stents.

The latest randomised controlled trial published is the ACHILLES, a prospective multicentre randomised study in which 99 patients were treated with sirolimus-eluting stents versus 101 patients treated with PTA were compared. The authors considered as a primary end-point 1-year in-segment binary restenosis evaluated by angiographic measurements [11]. In this randomised controlled trial, results were completely in favour of DES (binary restenosis: $22.4 \%$ sirolimus-eluting stents vs $41.9 \%$ PTA; $P=0.019$ ). Also, in diabetic patients, the most critical, intention-to-treat analysis showed better binary restenosis and other angiographic endpoints for DES than for BMS (i.e. vessel patency: $75 \%$ DES vs $57.1 \%$ BMS; $P=0.025)$. Nevertheless 1 -year clinical results did not show significant differences in terms of death (10.1 vs $11.9 \% ; P=0.822$ ), clinically driven target lesion revascularisation (10.0 vs $16.5 \% ; P=0.257)$ and index-limb amputation (13.8 vs $20.0 \% ; P=0.307$ ).
On the basis of these randomised controlled trials and other published studies [5, 9-15], features of DESs for below-theknee lesions may be summarised as follows:

Angiographic and clinical results

Primary patency rate at 3-years of follow-up was reported by Karnabatidis et al. [15] (29.7 \% DES vs $20.6 \%$ BMS; $P<0.0001$ ); the 1-year patency rate was between $75.0 \%$ (ACHILLES [13]) and $86 \%$ reported by Siablis et al. [14]

Target lesion revascularisation was between $8.7 \%$ (DESTINY) and $13.8 \%$ (YUKON) $[9,10]$.

However, in long-term studies, limb salvage (YUKON: sirolimus-eluting stents $98.7 \%$ vs BMSs $94.5 \%, P=0.17$; Siablis et al. [14]: sirolimus-eluting stents $82.0 \%$ vs BMSs $80.3 \%, P=0.507$ at 3 years; Karnabatidis et al. [15] reported major amputation-free survival of $77.1 \%$ vs $86.9 \%, P=0.2$ ) and mortality (YUKON: $26.3 \%$ sirolimus-eluting stents vs $32.3 \%$ BMSs, $P=0.6$; Siablis et al. [14]: $32.0 \%$ sirolimuseluting stents vs BMSs $29.3 \%, P=0.2$; Karnabatidis et al. [15] reported survival of $82.2 \%$ for DESs vs $65.7 \%$ for BMSs, $P=$ $0.9)$ did not differ as significantly different between DESs and BMSs at 3 years as that found in other studies [6]. 
From a technical point of view, some advantages and disadvantages are correlated with the use of DESs in the infrapopliteal region compared with balloons.

Technical advantages

- Possibility to cover all lesion lengths with a long DES

- Safe treatment of ostial lesions

- Overcome elastic recoil and vessel dissection

- Both balloon-expandable and self-expanding stents available

Technical disadvantages

- $\quad$ Stent fracture (ACHILLES trial $0.9 \%$ )

- Related risk of DES in-stent thrombosis that required additional antiplatelet therapy after stent deployment [16]

- Hindering of surgical landing zone for by-pass in the stented area

- Spot bail-out placement of DES has demonstrated lower cost-effectiveness than primary stenting [17]

\section{Drug-eluting balloon (DEB)}

The DEB represents the new frontier in the use of drugeluting devices. As most studies have been performed in the femoropopliteal region, there is a lack of data regarding the efficacy of DEB in the below-the-knee area. Besides the study limitations, initial results are very promising.

The Leipzig registry [18] included 104 patients (109 limbs) with critical limb ischaemia (82.6\%) or severe claudication $(17.4 \%)$ who were compared with an historical group treated with conventional angioplasty (PTA). Angiographic results showed the DEB group with a primary patency of $72.6 \%$ at 3 months versus $31 \%$ in the PTA group and a target lesion revascularisation of $17.3 \%$ at 1 year versus $50 \%$ for the PTA group. The limb salvage rate was $95.6 \%$ in the DEB group versus $100 \%$ in the PTA group, and the complete wound healing rate was $74.2 \%$ in DEB group versus $78.6 \%$ in the historical group [19]. Besides the large population, this registry has some limitations: non-randomised; poor homogeneity between the two cohorts; clinical results during the follow-up not significantly different between DEB and PTA.

One of the most recent studies is the DEBELLUM (Lower Limb Multilevel Treatment With Drug-Eluting Balloons) trial [20], which analysed 50 patients with femoropopliteal, infrainguinal and multilevel (concomitant femoropopliteal and below-the-knee) atherosclerotic disease. Patients were randomised between Medtronic In.Pact DEB and conventional angioplasty balloon (PTA). The preliminary 1- year results on the below-the-knee lesions confirmed a better outcome for DEB in terms of late lumen loss $(0.66 \pm 0.9 \mathrm{~mm}$ DEB vs $1.69 \pm$ $1.5 \mathrm{~mm}$ PTA; $P<0.05)$, target lesion revascularisation $(15.3 \%$ DEB vs $47.0 \%$ PTA; $P<0.05)$, and primary patency ( $84.6 \%$ DEB vs $41.1 \%$ PTA; $P<0.05$ ) [21]. However, major adverse events (major and minor amputation, thrombosis, death) did not different significantly in the two groups because of the limited number of lesions and patients involved.

The last data reported are from the DEBATE below-theknee (Drug Eluting Balloon For Below-The-Knee Angioplasty Evaluation) study [22]. It consists of a randomised, singlecentre study with 147 below-the-knee lesions randomised 1:1 between In.Pact DEB and standard PTA. The primary endpoint was 12 -month binary restenosis $(>50 \%)$; secondary endpoints were target lesion revascularisation and reocclusion rates. Only diabetic patients were enrolled in both groups, and most presented Texas wound ulcer class IID and IIID.

Significantly lower rates of restenosis were reported for DEB: $27 \%$ vs $74.3 \%(P<0.001)$ as well as for occlusions $17.6 \%$ vs $55.4 \%(P<0.001)$. Moreover the amputation rate $(0.0 \%$ vs $1.5 \% ; P=0.9)$, target lesion revascularisation ( $18.5 \%$ vs $43.3 \% ; P=0.003)$ and cumulative major adverse events ( $31 \%$ vs $51 \% ; P=0.05)$ have also been reported to be in favour of DEB.

On the basis of these trials and other published studies, we can summarise:

- Primary patency is currently between $73 \%$ (DEBATE [22]) and $84.6 \%$ at 12 months (DEBELLUM [21]).

- Target lesion revascularisation is between $15.3 \%$ (DEBELLUM [21]) and $17.6 \%$ (Leipzig Registry [18]).

- Limb salvage rates were not higher than those for standard PTA (95.6 \% in DEB vs $100 \%$ in the PTA; Leipzig Registry [18]); however, re-occlusion was more frequent with the standard PTA than with DEBs (55.4 \% PTA vs $17.6 \%$ DEB, $P<0.001$ in the DEBATE study [22]).

By analysing the current studies, technical advantages and disadvantages in the use of DEB versus stents may also be outlined:

Advantages

- Possibility of treating long lesions of up to $15 \mathrm{~cm}$ with a single balloon

- Capability of also treating very distal and foot lesions

- "Nothing left behind" concept

- Free surgical landing zone 
Disadvantages

- Flow-limiting dissection, especially in cases of very calcified arteries

- Calcified arteries can compromise the drug effect

\section{Discussion}

Current guidelines on peripheral arterial disease advocated primary angioplasty as the standard of care in the treatment of infragenicular arteries as it can guarantee an acceptable clinical outcome at a low procedural cost $[7,16]$.

Bail-out stenting is recommended only in cases of suboptimal angioplasty or flow-limiting dissection, and for this reason it is mainly based on spot stenting [7].

The DEB represents the natural evolution of standard angioplasty and is actually considered a valid emerging option, but results are still limited.

More data are available for DES, and level A (data derived from multiple randomised clinical trials or meta-analyses) and B (data derived from a single randomised controlled trial or large non-randomised studies) evidence supports the use of DES as a primary treatment for patients with critical limb ischaemia [5, 9-11, 13-15]. However some issues are still present, such as long and small vessels, fracture rate and compromised future surgical intervention.

In comparative studies (drug-eluting devices vs standard ones) the results are always in favour of the drug-eluting devices. However, clinical improvement has not been validated.

The DEB significantly reduces restenosis and re-occlusion rates versus PTA in complex below-the-knee lesions.

However, we have to consider that clinical improvement (limb salvage, Rutherford class and wound healing) is not always recognised as being better for drug-eluting devices. This can be also related to the multidisciplinary approach and therapy which may influence the clinical outcome of such patients [7, 16].

A limited number of clinical adverse events, which usually occur after endovascular therapy, lead to a nonstatistical difference between drug-eluting and noneluting devices.

In conclusion, balancing the specific features of both devices, we consider drug-eluting balloons to be the leading approach in below-the-knee disease because of the comparable primary patency rate and target lesion revascularisation with drug-eluting stents. However, new randomised trials comparing drug-eluting stents versus drug-eluting balloons seem to be mandatory to thoroughly evaluate efficacy in daily clinical practice.

\section{References}

1. Reekers JA, Lammer J (2012) Diabetic foot and PAD: the endovascular approach. Diabetes Metab Res Rev 28:36-39

2. Peregrin JH, Koznar B, Kovàc J et al (2010) PTA of infrapopliteal arteries: long-term clinical follow-up and analysis of factors influencing clinical outcome. Cardiovasc Intervent Radiol 33:720-725

3. Faglia E, Clerici G, Clerissi J et al (2007) When is a technically successful peripheral angioplasty effective in preventing above-theankle amputation in diabetic patients with critical limb ischaemia. Diabet Med 24:823-829

4. Park SW, Kim JS, Yun IJ et al (2013) Clinical outcomes of endovascular treatments for critical limb ischemia with chronic total occlusive lesions limited to below-the-knee arteries. Acta Radiol 54: 785-789

5. Feiring AJ, Krahn M, Nelson L, Wesolowski A, Eastwood D, Szabo A (2010) Preventing leg amputations in critical limb ischemia with below-the-knee drug-eluting stents: the PaRADISE (PReventing Amputations using Drug eluting StEnts) trial. J Am Coll Cardiol 55:1580-1589

6. Rand T, Uberoi R (2013) Current status of interventional radiology treatment of infrapopliteal arterial disease. Cardiovasc Intervent Radiol 36:588-598

7. Rooke TW, Hirsch AT, Misra S et al (2011) 2011 ACCF/AHA Focused Update of the Guideline for the Management of Patients With Peripheral Artery Disease (updating the 2005 guideline): a report of the American College of Cardiology Foundation/ American Heart Association Task Force on Practice Guidelines. J Am Coll Cardiol 58:2020-2045

8. Gertz ZM, Wilensky RL (2011) Local drug delivery for treatment of coronary and peripheral artery disease. Cardiovasc Ther 29:e54-e66

9. Bosiers M, Scheinert D, Peeters P et al (2012) Randomized comparison of everolimus-eluting versus bare-metal stents in patients with critical limb ischemia and infrapopliteal arterial occlusive disease. J Vasc Surg 55:390-398

10. Rastan A, Brechtel K, Krankenberg H et al (2012) Sirolimus-eluting stents for treatment of infrapopliteal arteries reduce clinical event rate compared to bare-metal stents: long-term results from a randomized trial. J Am Coll Cardiol 60:587-591

11. Scheinert D, Katsanos K, Zeller T et al (2012) A prospective randomized multicenter comparison of balloon angioplasty and infrapopliteal stenting with the sirolimus-eluting stent in patients with ischemic peripheral arterial disease: 1-year results from the ACHILLES trial. J Am Coll Cardiol 60:2290-2295

12. Bradbury AW, Adam DJ, Bell J et al (2010) Multicentre randomised controlled trial of the clinical and cost-effectiveness of a bypasssurgery-first versus a balloon-angioplasty-first revascularisation strategy for severe limb ischaemia due to infrainguinal disease. The Bypass versus Angioplasty in Severe Ischaemia of the Leg (BASIL) trial. Health Technol Assess 14:1-210

13. Norgren L, Hiatt WR, Dormandy JA et al (2007) Inter-Society Consensus for the Management of Peripheral Arterial Disease (TASC II). J Vasc Surg 45:1-67

14. Siablis D, Karnabatidis D, Katsanos K et al (2009) Infrapopliteal application of sirolimus-eluting versus bare metal stents for critical limb ischemia: analysis of long-term angiographic and clinical outcome. J Vasc Interv Radiol 20:1141-1150

15. Karnabatidis D, Spiliopoulos S, Diamantopoulos A et al (2011) Primary everolimus-eluting stenting versus balloon angioplasty with bailout bare metal stenting of long infrapopliteal lesions for treatment of critical limb ischemia. J Endovasc Ther 18:1-12

16. Tendera M, Aboyans V, Bartelink ML et al (2011) ESC Guidelines on the diagnosis and treatment of peripheral artery diseases: Document covering atherosclerotic disease of extracranial carotid and vertebral, mesenteric, renal, upper and lower extremity arteries: the Task Force 
on the Diagnosis and Treatment of Peripheral Artery Diseases of the European Society of Cardiology (ESC). Eur Heart J 32:2851-2906

17. Katsanos K, Karnabatidis D, Diamantopoulos A, Spiliopoulos S, Siablis D (2013) Cost-effectiveness analysis of infrapopliteal drugeluting stents. Cardiovasc Intervent Radiol 36:90-97

18. Schmidt A, Piorkowski M, Werner M et al (2011) First experience with drug-eluting balloons in infrapopliteal arteries: restenosis rate and clinical outcome. J Am Coll Cardiol 58:1105-1109

19. Schmidt A, Ulrich M, Winkler B et al (2010) Angiographic patency and clinical outcome after balloon-angioplasty for extensive infrapopliteal arterial disease. Catheter Cardiovasc Interv 76:1047-1054
20. Fanelli F, Cannavale A, Boatta E et al (2012) Lower limb multilevel treatment with drug-eluting balloons: 6-month results from the DEBELLUM randomized trial. J Endovasc Ther 19:571-580

21. Fanelli F, Cannavale A, Lucatelli P et al (2013) Lower limb multilevel treatment with drug eluting balloon: 12-month results from the "DEBELLUM" trial. Proc ECR 2013, Vienna

22. Liistro F, Porto I, Angioli P et al (2013) Drug-eluting balloon in peripheral intervention for below the knee angioplasty evaluation (DEBATE-BTK): a randomized trial in diabetic patients with critical limb ischemia. Circulation 128:615-621 